\title{
Grey correlation analysis of innovation investment and industrial economic growth in Shen-Guan-Hui economic circle
}

\author{
Deng Wenbo ${ }^{1,2}$
}

${ }^{1}$ School of Business, Macao University of Science and Technology, Macao

${ }^{2}$ Heyuan Polytechnic, Heyuan, Guangdong, 517000, China

wenbodeng@163.com

Author's brief introduction: Deng Wenbo (September 1975 -), male, Jiaoling, Guangdong Province, Ph.D. graduate student, Macao University of Science and Technology, research direction: innovation and regional economy

Keywords: Innovation input, Industrial economic growth, Grey correlation analysis.

\begin{abstract}
By studying the relationship between innovation investment and industrial economy, this paper discusses the promotion of scientific research expenditure and scientific research personnel investment on industrial economic growth. This paper analyzes the relationship between innovation input and industrial economic growth in Shenzhen, Dongguan, Huizhou, Heyuan and Shanwei by using grey relational analysis based on the relevant statistical data of Shen-Guan-Hui "3+2" economic circle from 2007 to 2016. The research shows that R\&D expenditure and scientific and technological personnel investment have positive correlation to the industrial economic growth of each city. However, there are significant differences in the level of industrial economic development. The notable factors of Shenzhen and Dongguan in developed areas are R\&D employees in scale enterprises. And the prominent factors for the rapid growth of industrial economy in Shanwei City and Huizhou City are the government appropriation for scientific research institutions and the expenditure on scientific research institutions. And the notable factor of Heyuan in less developed areas is the expenditure of scientific research institutions.
\end{abstract}

\section{Introduction}

Technological innovation is the leading force to promote regional economic development, and innovation investment is the main driving force to drive economic growth. The existing literature explores the significant factors of innovation input. For example, Hu Wei, Anning, Luo Shan and others think that the investment of scientific and technological personnel has greater impact on economic growth. Qiao Penghua and Zheng Jixing believe that the internal expenditure of R \& D expenditure has the most obvious effect on economic growth. In the aspect of innovation input driving industrial economic growth, Liu Aiqin thinks that R\&D expenditure and scientific and technological personnel investment have significant positive correlation with industrial economic growth, and the impact of scientific and technological activities is more significant.

Researchers put forward their own opinions on the significant factors of innovation input driving economic growth, but did not differentiate the significant factors of economic growth in different regions with different levels of economic development. This paper chooses Shen-Guan-Hui " $3+2$ " economic circle to study, because the industrial economic development level of the five cities in the economic circle gap is larger, more conducive to comparative analysis. Table 1 shows the industrial development of Shen-Guan-Hui " $3+2$ " economic circle.

Table 1. industrial economic situation of Shen-Guan-Hui "3+2" economic circle

\begin{tabular}{cccccc}
\hline District & $\begin{array}{c}2007 \\
\text { Industrial added } \\
\text { value(Hundred } \\
\text { million RMB) }\end{array}$ & $\begin{array}{c}\text { Industrial added } \\
\text { value(Hundred } \\
\text { million RMB) }\end{array}$ & $\begin{array}{c}\text { Industrial } \\
\text { added value } \\
\text { ranking(2016) }\end{array}$ & $\begin{array}{c}2016 \text { increased } \\
\text { by more than } \\
2007\end{array}$ & $\begin{array}{c}\text { Growth } \\
\text { rate } \\
\text { ranking }\end{array}$ \\
\hline Shenzhen & 3298.57 & 7108.87 & 1 & 2.16 & 4 \\
\hline Dongguan & 1430.60 & 2968.16 & 2 & 2.07 & 5 \\
\hline
\end{tabular}




\begin{tabular}{cccccc}
\hline Huizhou & 502.52 & 1763.69 & 3 & 3.51 & 2 \\
\hline Shanwei & 59.05 & 246.70 & 5 & 4.18 & 1 \\
\hline Heyuan & 147.80 & 351.00 & 4 & 2.37 & 3 \\
\hline
\end{tabular}

As can be seen from Table 1, Shenzhen and Dongguan rank first and second respectively in industrial added value, while Shanwei and Huizhou rank first and second in the growth rate. Through the analysis of the relationship between innovation input and industrial economic growth, this paper aims to analyze the significant factors of innovation input driving industrial economic growth in different economic development levels.

\section{Research method}

This paper makes an exploratory analysis of the relationship between innovation input and industrial economic growth to obtain significant factors, and it is more appropriate to adopt the grey relational analysis method.

Grey relational analysis is a method to analyze and determine the degree of influence among system factors or the contribution of factors to the main behavior of the system by means of grey relational degree. The basic idea is to judge the degree of correlation between sequences by the similarity of the geometric shapes of curves between reference sequences and several comparison sequences. There the higher the correlation degree is, the greater the contribution of the comparison series to the reference series. The steps of grey relational analysis are as follows.

\subsection{Deterministic analysis sequence}

Determine the reference sequence reflecting the behavior characteristics of the system and the comparative sequence that affects the behavior of the system. A sequence of data that reflects the behavior of a system is called a reference sequence. A series of data that affect the behavior of a system is called comparative series.

Set the reference sequence as $\mathrm{X}_{0}$, The observed data on the time series $\mathrm{K}$ are $\mathrm{x}_{0}(\mathrm{k})(\mathrm{k}=1,2,3 \ldots \mathrm{n})$, The reference sequence is: $\mathrm{x}_{0}=\left\langle\mathrm{x}_{0}(\mathrm{k}) \mid \mathrm{k}=1,2,3 \ldots \mathrm{n}\right\rangle$.

Set the comparison sequence as $\mathrm{X}_{\mathrm{i}}(\mathrm{i}=1,2,3 \ldots \mathrm{m})$, The observed data on the time series $\mathrm{K}$ are $\mathrm{x}_{\mathrm{i}}$, m comparison sequences: $X_{i}=\left\langle x_{i}(k) \mid k=1,2,3 \ldots n\right\rangle(i=1,2,3 \ldots m)$.

\subsection{Dimensionless transformation of variables}

Because the data dimension of each factor column in the system is different, it is not easy to compare directly. Therefore, in the analysis of grey relational degree, the data should be dimensionless. Its general expression is.

$$
\begin{aligned}
& X_{0}^{\prime}=\frac{X_{0}^{(k)}}{x_{0}(1)}=\left\{x_{0}^{\prime}(1), x_{0}^{\prime}(2), \ldots x_{0}^{\prime}(n)\right\}(k=1,2, \ldots n) \\
& X^{\prime}=\frac{X_{i}^{(k)}}{x_{i}^{(1)}}=\left\{x_{i}^{\prime}(1), x_{i}^{\prime}(2), \ldots x_{i}^{\prime}(n)\right\}(i=1,2, \ldots m ; k=1,2, \ldots n)
\end{aligned}
$$

\subsection{Sequence of difference}

$$
\begin{aligned}
& \Delta_{i}(k)=\left|x_{0}^{\prime}(k)-x_{i}^{\prime}(k)\right| \\
& \Delta_{i}=\left(\Delta_{i}(1), \Delta_{i}(2), \ldots, \Delta_{i}(n)\right)(i=1,2, \ldots, m)
\end{aligned}
$$

2.4 Maximum difference between two poles and minimum difference between poles

$$
\begin{aligned}
\Delta \max & =\max _{i} \max _{k} \Delta_{i}(k) \\
\Delta \min & =\min _{i} \min _{k} \Delta_{i}(k)
\end{aligned}
$$

2.5 Calculating correlation coefficient between sequence and reference sequence 
Calculation formula $\mathcal{E}_{i}(\mathbf{k})=\frac{\Delta \min +\rho \Delta \max }{\Delta \Delta_{i}(k)+\rho \Delta \max } \quad, \quad \rho(0<\rho<1)$

Among them, $\xi_{i}(k)$ is the relative value of the comparison sequence $\mathrm{Xi}$ and the reference sequence $\mathrm{X}_{0}$ in different years is called the correlation coefficient. $\rho(0<\rho<1) \quad \rho$ is the resolution coefficient. Generally take $\rho=0.1-0.5$, in order to have higher resolution, get 取 $\rho=0.1$.

\subsection{Calculating correlation degree}

Because the correlation coefficient is the value of the degree of correlation between the reference sequence and the sequence at each time, it has many, and the information is too scattered to make a holistic comparison. Therefore, the average value is calculated as a quantitative representation of the degree of correlation between the reference sequence and the sequence of numbers. The correlation degree RI formula is as follows.

$$
\gamma_{\mathrm{i}}=\frac{1}{\mathrm{n}} \sum_{\mathrm{k}=1}^{n} \xi_{i}(k) \quad(i=1,2, \ldots m ; k=1,2, \ldots n)
$$

\section{Grey correlation analysis between innovation input and industrial economic growth}

Industrial added value is chosen as the consideration index for industrial economic growth. Innovation input can be divided into funds input and personnel input, in which funds input select three indicators: government funding for scientific research institutions, scientific research institutions, $R \& D$ expenditure of scale enterprises. The personnel input is selected as two indicators: scientific and technological personnel of scientific research institutions and R\&D personnel of large-scale enterprises. All the indicators are derived from the statistical yearbook of Guangdong over the years.

Firstly, this paper takes industrial added value as reference series $\mathrm{X}_{0}$, and selects scientific and technological personnel, government funds allocated by scientific research institutions, expenditure on scientific research institutions, R\&D personnel of scale enterprises, and internal expenditure on $\mathrm{R} \& \mathrm{D}$ funds of scale enterprises as comparison series, which are respectively recorded as $\mathrm{X}_{1}, \mathrm{X}_{2}, \mathrm{X}_{3}$, $\mathrm{X}_{4}$ and $\mathrm{X}_{5}$.

Secondly, because the meanings of each index are different and the units are different, in order to facilitate the comparison, the dimensionless processing is carried out according to formula (1)(2).

Thirdly, the absolute difference between the comparison sequence and the reference sequence is calculated, and then the correlation coefficient is calculated according to formula (3). The correlation coefficient matrix is obtained by taking $\rho=0.1$.

Finally, according to formula (4), the correlation degree of each series can be calculated. The result is shown in Table 2.

Table 2. Correlation between innovation input and industrial added value in Shen-Guan-Hui economic circle

\begin{tabular}{cccccc}
\hline District & $\mathrm{X}_{1}$ & $\mathrm{X}_{2}$ & $\mathrm{X}_{3}$ & $\mathrm{X}_{4}$ & $\mathrm{X}_{5}$ \\
\hline Shenzhen & 0.2647 & 0.2691 & 0.2671 & 0.6241 & 0.4130 \\
\hline Relevance ranking & 5 & 3 & 4 & 1 & 2 \\
\hline Dongguan & 0.3698 & 0.3995 & 0.4369 & 0.6333 & 0.5072 \\
\hline Relevance ranking & 5 & 4 & 3 & 1 & 2 \\
\hline Huizhou & 0.2657 & 0.4488 & 0.4507 & 0.4139 & 0.4075 \\
\hline Relevance ranking & 5 & 2 & 1 & 3 & 4 \\
\hline Shanwei & 0.3447 & 0.6600 & 0.6458 & 0.3713 & 0.4079 \\
\hline Relevance ranking & 5 & 1 & 2 & 4 & 3 \\
\hline Heyuan & 0.4539 & 0.4180 & 0.6150 & 0.3882 & 0.2642 \\
\hline Relevance ranking & 2 & 3 & 1 & 4 & 5 \\
\hline
\end{tabular}




\section{Summary}

The empirical analysis results show that the influencing factors of innovation input are different in different regions with different levels of economic development.

Firstly, the R\&D activities personnel and R\&D expenditure of scale enterprises in Shenzhen and Dongguan, which are the two cities with the strongest industrial economic strength, rank in the first two places respectively. This shows that the innovation input of scale enterprises in developed industrial areas has a more obvious driving effect on industrial economic growth, and the R\&D personnel of enterprises play a more significant role.

Secondly, from the industrial economic growth rate of Shanwei and Huizhou, the top two factors are government funding for research institutions and expenditure on research institutions, Huizhou's funding for research institutions is more significant, and Shanwei's expenditure on research institutions is more significant. This shows that increasing government funding and expenditure on scientific research institutions can drive the rapid growth of industrial economy. It is suggested that incentive policies should be adopted to enhance the innovation capability of large-scale enterprises.

Finally, the first two factors of innovation input in Heyuan are the expenditure of scientific research institutions and the personnel of scientific and technological activities of scientific research institutions. This shows that the ability of innovation input to drive industrial economic growth in less developed Heyuan City mainly depends on the R\&D capability of scientific research institutions. It is suggested that the government should increase investment in scientific research to drive the growth of industrial economy.

\section{Acknowledgement}

This work was financially supported by the key project of Heyuan philosophy and Social Sciences 13th Five-Year plan 2016 (HYSK16Z01) and the Scientific and Technological Projects of Heyuan Polytechnic (Project No. 2017_sk01).

\section{References}

[1] Chen Xin,Huang Taozhen. Research on the contribution of technological innovation to economic growth in Jiangsu and Zhejiang[J]. Science \& Technology Progress and Policy, vol. 27(21)pp.61-64,2010.

[2] Jiang Miaomiao,Lu Xinguo,Wang Xiangqian. Study of the Contribution Rate of Technology Innovation for Economic Growth [J].Journal of Huaiyin Institute of Technology, vol.25(8) pp.58-64,2016.

[3] $\mathrm{Hu}$ Wei, Correlation analysis between science and technology input and economic growth in Guangdong [J]. Science and Technology Management Research, (9)pp.116-117,2008.

[4] An Ning,Luo Shan. An empirical analysis of the relationship between Guangdong's science and technology input and economic growth[J]. Science and Technology Management Research, (12)pp.190-192,2008.

[5] Qiao Penghua,Zheng Jixing. Grey relational analysis between science and technology input and economic growth in Heilongjiang[J]. Science and Technology Management Research,(22)pp.59-62,2010.

[6] Liu Aiqin. Grey correlation analysis between science and technology input and industrial economic growth in Shandong[J]. Science and Technology Management Research,(01)pp.107-110,2008.

[7] Jing Xue-qing, A grey comparative analysis of the type structure of R\&D input and economic growth in China, Journal of Southeast University(Philosophy and Social Science), vol. 15(06), 
pp. 26-29, 2013. 